\title{
Tutoria a Distância: sobre o Trabalho e a Docência
}

\section{Distance Tutoring: about Working and Teaching}

\author{
Fabio Alexandre Dziekaniak \\ Universidade Federal do Rio Grande \\ Vanise dos Santos Gomes \\ Universidade Federal do Rio Grande \\ Luciana Netto Dolci \\ Universidade Federal do Rio Grande
}

Resumo: Este artigo objetiva compreender os sentidos do trabalho da tutoria na Educação a Distância e o comprometimento com os diversos artefatos que envolvem o desenvolvimento desta modalidade de ensino. As reflexões são construídas a partir dos relatos de cinco tutoras a distância que atuaram no curso de Especialização em Educação de Jovens e Adultos na Diversidade, vinculado ao Sistema Universidade Aberta do Brasil - UAB/CAPES. Os dados foram coletados a partir de entrevistas semi-estruturada. A análise dos dados deu-se por meio da Análise Textual Discursiva. Os resultados evidenciam os diferentes papéis que as tutoras assumem na organização da Educação a Distância, questionando principalmente as influências do Modo de Produção Capitalista na estrutura da EaDConstatou-se que tal modo de produção influencia o trabalho das tutoras, que no âmbito educacional é um trabalho terceirizado, uma das conseqüências dalógica capitalista da precarização e exploração da mão de obra trabalhadora.

Palavras chave: Educação a Distância. Tutoria. Trabalho Precarizado.

Abstract: This article aims to understand the meanings of the mentoring work in distance educationand the commitment to the several artifacts necessary to the development of this type of education with quality. The reflections are approached from the reports of five distance tutors who worked in the course of Specialization in Youth and Adult Education in Diversity, linked to the System Open University of Brazil - UAB / CAPES. Data were collected from semistructured interviews with the study subjects. The data analysis was made by means of Discourse Text Analysis. The results the different roles the tutors play in the Distance Education organization, mainly questioning the influences of the Capitalist Mode of Production in the distance education structure. The route of research allowed to understand that this mode of production has consequences for the work of tutors, which is established in the educational field as an outsourced work, developed through provision of temporary services. This work characterizes the capitalist logic of casualization and labor exploitation.

Keywords: Distance Education. Mentoring. Precarious work. 


\section{Introdução}

O trabalho que envolve investigações relativas à Educação a Distância é algo que nos mobiliza enquanto pesquisadores. Isso porque são diversos os sujeitos com quem dialogamos e que vivenciam o contexto em especial. Em suas narrativas, expressam o quão tênue parece ser a diferença entre educação presencial e a distancia, uma vez que ambas as ideias mesclam-se ao aturem em cursos EaD.

O presente artigo tem o objetivo de compreender os sentidos do trabalho de profissionais que atuam na tutoria a distancia, bem como o comprometimento com os diversos artefatos que envolvem o desenvolvimento com qualidade desta modalidade de ensino. Escolhemos, aqui, apurar a escuta para um grupo em especial, aqueles sujeitos que acompanham, na plataforma virtual, a aprendizagem dos estudantes.

As discussões presentes foram construídas a partir de pesquisa qualitativa realizada junto a cinco tutoras a distância, atuantes na primeira edição do curso de Especialização em Educação de Jovens e Adultos na Diversidade (realizado entre agosto de 2010 e junho de 2012). Foram convidadas a participar da pesquisa todas as tutoras envolvidas no curso desde seu início até sua finalização garantindo, assim, uma importante inserção nas ações solicitadas. Ainda, considerou-se o interesse das tutoras em aturem como sujeitos de pesquisa, reduzindo o número de dez tutoras para cinco.

Objetivou-se, com esta pesquisa, compreender, por meio de entrevistas semi-estruturadas, os sentidos que são atribuídos pelas tutoras a distância ao trabalho desenvolvido por elas na tutoria, levando em consideração as ações competentes a eles na função de tutor, a estrutura organizacional dos cursos de graduação e pós-graduação públicos oferecidos a distância e realizados com recursos do Programa Universidade Aberta do Brasil - UAB, além de suas percepções acerca do processo educativo realizado na modalidade a distância.

Para respaldar as análises e estudos realizados durante a pesquisa, foram utilizados teóricos que versam sobre: Educação a Distância - EaD tais como Ligia Leite e Aparecida Dias (2010), João Mattar (2012), José Manuel Moran e José Armando Valente (2011) entre outros autores cujas discussões contribuem para avançarmos na compreensão da ideia de trabalho e da profissão docente, tais como Ricardo Antunes (2009) e Miguel Arroyo (2010),

Além do embasamento teórico que alimenta as discussões tecidas, foram utilizados estudos sobre Análise Textual Discursiva - ATD, cunhada por Moraes e Galiazzi (2007), para compor o corpus de análise dos dados produzidoscoletados. Neste artigo, serão abordadas discussões sobre "Tutoria a distância: questões que influenciam as condições de trabalho", construído a partir dos relatos a respeito da estrutura organizacional da EaD, funções do tutor e identidade docente na tutoria. Os autores anunciados anteriormente contribuem para compor as análises da fala dos sujeitos da pesquisa, possibilitando, assim, a ampliação do debate sobre trabalho e docência. Com a análise emergiram as duas categorias, a saber: Tutoria e docência: questões que caracterizam o trabalho do tutor a distância e Dialogando sobre a (des)valorização do trabalho na Tutoria a distância que discorrem com os teóricos que compõem este estudo, sustentando as discussões realizadas. 
Cabe ressaltar que os dados utilizados para a construção desta escrita fazem referência às experiências individuais dos sujeitos de pesquisa que contextualizam as ações desenvolvidas na tutoria a distância no curso de Especialização em Educação de Jovens e Adultos na Diversidade, mas também em outros cursos em que tiveram a oportunidade de atuar.

\section{Tutoria e docência: questões que caracterizam o trabalho do tutor a distância}

Iniciamos as discussões enfatizando uma questão encontrada nos relatos de todas as tutoras entrevistadas, sendo exemplificada, neste momento, pelas palavras de Leila ${ }^{1}$, tutora desde 2009. Tal fala traduz o sentido que dá ao trabalho desenvolvido na tutoria: "[...] na verdade eu pensava em tutoria como professora sempre... porque o tutor, ele é um professor". Esse fragmento faz menção à problematizações acerca da construção da identidade do profissional que atua na tutoria a distância. Por que essa afirmação? Tutor não é um professor?

As experiências vivenciadas e as ações desenvolvidas dizem que sim, mas a legislação que rege a educação a distância não considera o tutor dessa maneira, ficando a cargo de cada instituição a interpretação a respeito do real papel do tutor no processo de aprendizagem dos alunos. Desta maneira, entendemos importante discutir o que diz a legislação a respeito do profissional tutor a distância, para posteriormente relacionar as experiências das tutoras ao contexto organizacional da EaD.

Conforme os Referenciais de Qualidade para o Ensino Superior a Distância do MEC (2007), documento que delibera a respeito da organização de cursos superiores à distância no país, o tutor à distância, ou simplesmente tutor, como mencionado no documento, tem, como principal função, o esclarecimento de dúvidas por meio dos recursos de comunicação disponíveis (fóruns via Internet, telefone ou videoconferência). Mattar (2012) aponta que as múltiplas interpretações a respeito da função da tutoria entram em conflito na ação efetiva do trabalho desenvolvido por eles, tanto no que se refere à atividade docente, quanto nas questões financeiras, sendo interpretada em muitos momentos de maneira pejorativa. E ainda complementa: "A escolha do termo é infeliz".

Alice comenta a respeito do termo: "[...] a própria escrita da palavra é importante e a escrita diz que tu é tutor". Leila também diz: "[...] e outra é o nome tutor, porque aí tutor parece monitor mesmo; por isso que eu falei que é importante ter a palavra professor".

Não é por acaso que a afirmação primeira de Leila remete à identidade do tutor como professor. Aquele que vivencia, na prática, a experiência da tutoria, não consegue se desligar da docência como fio condutor de seu trabalho, pois não existe maneira de contribuir com a aprendizagem de outros sujeitos senão assumindo-se como parte responsável do processo de formação. Daiane corrobora com essa perspectiva, dizendo que:

\footnotetext{
${ }^{1}$ Os nomes utilizados para designar as tutoras que participaram da pesquisa são fictícios. As citações dos sujeitos de
} pesquisa são apresentadas em itálico ao longo do texto. 
"[...] a gente tem que ter responsabilidade. Eu penso que é responsabilidade das pessoas, tanto a minha responsabilidade enquanto tutora, de dar esse retorno pras pessoas, né, das tarefas, das atividades que tão sendo feitas, dos textos que tão sendo lidos; e a gente tá fazendo lá o fórum que a gente tá fazendo uma discussão, tá fazendo um trabalho com perguntas e tal sobre aquela teoria ali. Eu tenho que ter responsabilidade também de devolver aquelas respostas pra eles, né, e como é que tá aquele sentido ali?"

Em contraposição às certezas de Leila e aos entendimentos de Daiane sobre suas responsabilidades, está o engessamento observado por Alice com relação ao termo tutor: "[...] na tutoria nós sabemos que nós somos tutores e que estamos fazendo a intermediação entre o aluno e o professor". Daiane diz que "[...] muitas e muitas vezes a gente passou por várias discussões sobre isso. Qual é o papel real do tutor? E até a gente teve várias formações com relação a isso e foi muito legal, e acho que tem que ter mesmo". O conjunto de atribuições vinculadas ao tutor faz dele um profissional que desenvolve muito além da intermediação entre professor e aluno. Na fala de Daiane, fica evidente que o papel do tutor assume diferentes funções, cabendo às instituições encontrar um tom que possibilite certa homogeneidade nas atividades desenvolvidas por esses profissionais em todos os cursos oferecidos.

Por outro lado, o fato de cada profissional possuir diferentes atribuições pode significar que a própria atividade docente está fragmentada. Isso porque as funções pedagógicas do professor são retalhadas em uma série de tarefas que vão desde o planejamento, elaboração do conteúdo, construção do material, mediação, avaliação e administração, desenvolvidas por diferentes pessoas (MATTAR, 2012). Essas funções nas mãos de diferentes profissionais podem ser consideradas como consequências do Modo de Produção Capitalista no fazer docente, em que a produção em série aligeira a elaboração do produto fim. No caso da EaD, especificamente, possibilita a ampliação do número de estudantes atendidos, com redução dos custos com pessoal qualificado para o atendimento dessa produção em massa.

"[...] como tutora, eu faço parte de muita coisa ali, além de mediar tudo que ele tá aprendendo, tudo que ele tá construindo... Eu faço parte daquela disciplina, porque eu me aproprio dela. Eu adoro ver o olhinho aberto antes dos alunos pra poder saber o que que tá acontecendo; pra poder ir ali e cobrar e esse contato que a gente tem direto com eles. Assim, essa linha de frente que é o grande, é a grande diferença. Isso faz com que eu não seja atriz coadjuvante desse palco que é a EaD!" (Flávia).

O relato de Flávia demonstra o quão integrado é o trabalho desenvolvido pelos tutores a distância. O acompanhamento da plataforma de aprendizagem antes do início da disciplina, durante sua realização, a partir das interações com os estudantes e ao final das disciplinas com avaliação e atribuição de notas, realmente não permite que o tutor seja um coadjuvante no processo de aprendizagem. Nesse contexto, vemos que há algo incoerente nessa divisão de papéis diferentes para a realização da ação docente, que é única. Essa é uma estrutura justa? Possibilita qualidade no processo educativo?

Tais questionamentos nos apontam para outras problemáticas, também evidenciadas pelos sujeitos de pesquisa, que se referem à organização e estrutura da EaD a partir das 
especificações da UAB e do curso de Especialização em Educação de Jovens e Adultos na Diversidade.

Duas posturas diferentes são apresentadas pelas tutoras com relação à estrutura da EaD. Flávia relata sobre a organização da UAB:

"[...] conhecendo assim a UAB, tudo que envolve, porque se a gente parar pra pensar tudo que envolve uma disciplina ir pro ar... desde o pessoal que organiza, o pessoal da correção... quanta coisa envolve uma disciplina estar ali, né, um site estar aberto pra ti aprender com ele, então os sentidos são inúmeros, mas acho que os mais pontuais são esses, a questão da organização."

Nas palavras de Flávia, podemos perceber a necessária participação de diferentes profissionais para a realização de um curso na modalidade a distância. Mattar (2012) anuncia, de forma bastante contundente, que a estrutura da EaD reforça o rebaixamento do trabalho docente, tanto com relação à remuneração, quanto nas formas de contratação, que são realizadas em regime temporário e com pagamento de bolsas. Essa situação estende-se também aos profissionais que atuam nos bastidores da educação a distância, como é o caso de revisores, equipes administrativas, conforme citado por Flávia, além de equipes técnicas e pedagógicas que apoiam professores e tutores para a realização dos cursos.

É possível, porém, pensar em alternativas para a realização de diferentes modelos de Educação a Distância. Em uma mesma instituição, encontramos cursos em que a hierarquia assume múltiplas características, pois depende da organização estabelecida por cada equipe diretiva. Não é foco deste artigo analisar as propostas de organização dos cursos, mas, sim, pensar que a organização interfere diretamente na função e atuação do tutor a distância.

Arroyo (2010) problematiza a afirmação da categoria docente como categoria fragmentada, dizendo "temos muitos magistérios" e "o ofício de mestre é o mesmo". Dentre as colocações do autor, destaco as reflexões acerca do magistério de nível superior, pois ele explica que a porta de entrada para as universidades são os concursos públicos, diminuindo dessa forma as tensões acerca do exercício da docência, porque todos são professores. Entretanto, vemos a inserção da EaD nas Instituições de Ensino Superior públicas e a participação de profissionais com formação, aptos a exercer a docência e atuando ativamente nos processos de construção de aprendizagem, sendo submetidos a diferentes formas de organização conforme o curso em que estão atuando. Recorro mais uma vez a Arroyo (2010) e questiono: O ofício de mestre é o mesmo?

Alice apresenta uma visão bastante crítica com relação a EaD:

"[...] eu participava com outras pessoas que comungavam da mesma ideia que eu de uma crítica forte de contestação à Educação a Distância dentro das Universidades Públicas Federais, já que na época contestávamos a baixa qualidade e a mercantilização da universidade no Brasil... a certificação e não a qualificação, então essa discussão estava bem forte e isto talvez nos anos 2003, 2004."

Na mesma direção de Mattar (2012), Alice pensa uma educação mercantilizada, que na EaD baseia-se no que o autor nomeia como cursos on demand e just-in-time, ou seja, oferta de 
cursos por demanda, no momento exato. Nessa perspectiva, vemos que a EaD e a UAB estão a serviço do mercado, oferecendo formação por demanda, conforme a necessidade de produção de mão de obra para executar determinada atividade.

Outra questão importante é que nessa organização não é conveniente manter profissionais com vínculo empregatício para a atuação na Educação a Distância. Por isso, os contratos temporários assumem papel essencial para permanência de profissionais na modalidade a distância. Esse regime de contratação alimenta o que Antunes (2009) chama de precarização do trabalho, termo oriundo da análise das relações de trabalho no Modo de Produção Capitalista, relacionado ao terceiro setor em que a mão de obra é terceirizada e abriga uma parcela de "trabalhadores desempregados pelo capital".

Neste sentido, no contexto educacional, a prestação de serviços temporários materializa-se nas ações desenvolvidas pelos tutores, seguindo a lógica da substitutibilidade e do uso e descarte da mão de obra trabalhadora.

A este respeito, Antunes (2009) afirma que o terceiro setor não tem a capacidade de substituir a classe trabalhadora no Modo de Produção Capitalista. Entretanto, compreendemos que espaços como a Educação a Distância abrigam trabalhadores informais, tornando as relações de trabalho injustas, na medida em que há a desvalorização financeira e distorção no que se refere à função docente.

\section{Dialogando sobre a (des)valorização do trabalho na Tutoria a distância}

Conforme Mattar (2012), o contexto de exploração na Educação a Distância é tão acentuado que um tutor obtém apenas $10 \%$ da remuneração equivalente do salário de um professor concursado do ensino superior presencial na mesma instituição pública em que são oferecidos os cursos na modalidade a distância. Além disso, o tutor não possui nenhum tipo de benefício como férias, décimo terceiro salário ou vínculo empregatício, passando ainda pela instabilidade no pagamento durante o período de atuação, pois a remuneração pelo trabalho desenvolvido é realizado através de bolsas ${ }^{2}$ que ocasionalmente atrasam.

Essa problemática foi vivenciada pelas tutoras, conforme relata Alice:

"[...] nós éramos os tutores. Até pela questão da bolsa oferecida pelo MEC já te coloca na tua função de tutor, não na tua condição de professor. [...] Teve momentos que teve colegas que tavam com problemas sérios de financeiro, porque foram se endividando; e nós praticamente ficamos quase três meses sem receber bolsa e sem notícia das bolsas, que era o mais grave."

Outra questão que legitima a desvalorização no trabalho dos tutores é o reajuste nas bolsas de tutoria. O último reajuste concedido foi deliberado pela Resolução CD/FNDE no 8, de 30 de

\footnotetext{
2 O financiamento do curso de Especialização em Educação de Jovens e Adultos na Diversidade foi realizado através da Secretaria de Educação Continuada, Alfabetização, Diversidade e Inclusão - SECADI, em parceria com a Universidade Aberta do Brasil - UAB e as bolsas pagas através do Fundo Nacional de Desenvolvimento da Educação - FNDE, até o ano de 2011, e posteriormente pela CAPES - Coordenação de Aperfeiçoamento de Pessoal de Nível Superior.
} 
abril de 2010 e desde então os valores ${ }^{3}$ pagos continuam os mesmos, sem perspectiva de alteração. São quase quatro anos em que muitos cursos iniciaram e já foram concluídos, muitos profissionais atuaram como tutores e o reconhecimento financeiro, parte essencial no mundo do trabalho em que o profissional vende sua mão de obra para subsidiar seu sustento, continua em constante defasagem.

As falas citadas anteriormente traduzem o sentimento de desprestígio da função do tutor, muito embora a fala das tutoras esteja sempre carregada de um sentimento positivo, de confiança no trabalho realizado, de orgulho por fazer parte da formação de muitas pessoas e também pela esperança de que o trabalho possa ser mais valorizado "[...] porque é um trabalho que se faz; não é um bico a educação a distância; nem pode ser um bico, até porque nós professores fazemos bico às vezes, mas nesse caso não pode ser um bico" (Alice).

O termo "bico" que Alice utiliza para se referir ao trabalho remete às teorizações de Antunes (2013) a respeito do valor do trabalho no sistema de produção capitalista. Tal valor está ligado à quantidade de esforço empregado para a realização de uma dada atividade. Assim, tal valor do trabalho é um valor relativo, pois abriga em si a quantidade de trabalho incorporada em todo o processo de desenvolvimento do produto final. A exemplo, o autor cita a produção do tecido de algodão, sendo necessária a produção do fio que, para ser produzido, necessita da matéria prima, que é o algodão, o fuso para tecer o fio e ainda o tempo de produção do fio. Logo, na produção do tecido estão contidos tanto o tempo de produção do fio com as ferramentas necessárias para tal como também o tempo de produção do tecido de algodão (ANTUNES, 2013).

Entretanto, no exemplo citado acima, a valorização do trabalho está relacionada com o processo produtivo, gerando não somente valores de uso ao produto, mas também valores de troca, visando a comercialização e a geração de lucros com o produto fim. Na EaD não estamos lidando diretamente com a produção propriamente dita e por isso Antunes (2013) diz, seguindo a teoria marxista, que o trabalho no setor de serviços, como é o caso da educação, assume uma característica nomeada como trabalho improdutivo, ou seja, aquele que não gera valor de troca diretamente, mas contém em si o valor de uso aplicado para a produção da mais valia. 0 que a valorização do trabalho do tutor contém em si é um valor social na medida em que estão depositados sob suas responsabilidades a formação de outros profissionais que possam atuar no mercado a serviço do capital.

Mesmo diante de tantas adversidades com relação ao reconhecimento, remuneração e legitimação da ação docente das tutoras, os sujeitos desta pesquisa apresentam uma visão, diríamos, otimista sobre a Educação a Distância. Expressam que as experiências que tiveram no curso de Especialização em Educação de Jovens e Adultos são diferentes de outras. Salientam, elas, aspectos como: seriedade do trabalho desenvolvido, liberdade de participação nas disciplinas, decisões e atividades relacionadas ao planejamento e desenvolvimento das

\footnotetext{
${ }^{3} \mathrm{O}$ valor das bolsas para tutoria a distância eram de $\mathrm{R} \$ 600,00$ estando fixadas em $\mathrm{R} \$ 765,00$ desde o reajuste realizado no ano de 2010, pagos mensalmente. O número de bolsas varia de acordo com a quantidade de horas em cada disciplina,
} sendo que a cada 15 horas é paga uma bolsa, não podendo exceder mais do que três bolsas por disciplina. 
ações pedagógicas, sentimento esse que se estende à universidade à qual estavam vinculados no momento de sua atuação.

"[...] eu acho que tem toda uma seriedade assim no curso a distância, principalmente na FURG, tanto que é reconhecido nos polos, né; todos os polos dizem isso da seriedade desse curso a distância" (Leila).

"[...] e percebi a profundidade do trabalho, a qualidade, o comprometimento, a exigência em relação aos alunos; eu percebi altíssima exigência em relação aos alunos" (Alice).

Comprometidas e engajadas com a formação dos estudantes que realizaram o curso de Especialização em Educação de Jovens e Adultos na Diversidade, as tutoras ressaltam a qualidade do curso, reflexo do trabalho que foi desenvolvido por elas juntamente ao grupo de professores que ministravam as disciplinas. Leila diz: "[...] porque eu acho que a EJA, e principalmente a EJA na Diversidade, tem muito de educação popular e eu acredito e trabalho dentro da universidade, acreditando na educação popular".

Em muitos momentos, percebíamos que as tutoras falavam com carinho das ações que desenvolviam na tutoria, o que nos fazia questionar se realmente o trabalho na tutoria a distância estava inserido em um contexto de exploração tão agressivo. Pareciam estar satisfeitas com o curso e, sobretudo com o contato junto aos estudantes. Alegravam-se com as possibilidades de ampliar debates e percebiam-se como satisfeitas por fazer parte da "equipe da EJA". São constatações, estas, que solicitam outra importante reflexão que diz respeito à a ingenuidade com relação a real situação de exploração a que, em alguma instância, podemos estar submetidos.

Entendemos que é na atividade prática exercida pelos trabalhadores de maneira ingênua e naturalizada que estão concentradas as formas de dominação do Modo de Produção Capitalista. Assim, por meio da alienação do trabalhador é que o sistema se alimenta e luta para sobreviver (ANTUNES, 2009). Amar a profissão, gostar do que faz, identificar-se com o trabalho é essencial para que depositemos a mais intensa carga de qualidade ao que fazemos. Entretanto, sujeitar-se às regras do capitalismo sem questionar a desvalorização do nosso trabalho e as condições impostas pelo sistema impede que alcancemos a plenitude de nossa capacidade reflexiva.

Antunes (2009, p.132) confirma:

[...] naquela parcela aparentemente mais "estável" e inserida da força de trabalho que exerce o trabalho intelectual abstrato o quadro é ainda mais intenso nos estratos precarizados da força humana de trabalho, que vivenciam as condições mais desprovidas de direitos e em situação de instabilidade cotidiana, dada pelo trabalho part time, temporário, etc.

Não basta refletir sobre nossas ações isoladamente, mas sim a partir do contexto social do qual fazemos parte para que as condições de opressão possam ser estranhadas e superadas (LOUREIRO, 2004).

Ao encontro do que nos diz Loureiro (2004, p.46), 
O resultado esperado nesse processo é adquirir a capacidade de articularmos o específico com o global, o conjuntural com o estrutural, reformular valores e comportamentos, repensar o sentido da vida e de nossas relações na natureza e atuar politicamente na sociedade.

É neste sentido que são tecidas as reflexões deste artigo, pois de nada adianta compreender que mesmo em uma situação tão desfavorável o trabalho dos tutores aconteça com qualidade e comprometimento, sem questionar a alienação e precarização a que estão submetidos.

Evidenciamos que, neste contexto investigado, a tutoria a distância é um trabalho docente. Sendo assim, também compreendemos que a estrutura organizacional da Educação a Distância vinculada ao Sistema Universidade Aberta do Brasil, baseia-se na terceirização do trabalho docente na formação de nível superior. Isso ratificando a desvalorização dos profissionais que atuam na modalidade e na manutenção contínua da exploração dos tutores.

Importa pensar alternativas que qualifiquem a Educação a Distância com o intuito de possibilitar a formação inicial e continuada de profissionais em regiões em que não existem instituições de ensino superior públicas. Isso sem subjulgar o exercício legítimo da ação docente desenvolvida pelos tutores, menosprezando financeira e pedagogicamente a atuação séria e responsável realizada por eles.

Os próprios tutores refletem a respeito da institucionalização da função que desempenham, pensando na qualidade do trabalho desenvolvido e também na maior valorização profissional. Flávia diz:

"Era uma boa, assim de ter tutores de carreira assim, porque é um trabalho muito bom, muito bom mesmo, assim, de organizarem o quadro, que a gente pudesse se dedicar mais pra isso, porque na verdade, por mais que seja... hãã é um trabalho, estou realizando um trabalho, mas não é... eu não vivo disso, né, ele é apenas um complemento."

A necessidade de institucionalização da profissão do tutor vem sendo amplamente discutida, principalmente no âmbito da Associação Nacional dos Tutores de Educação a Distância ANATED, entidade que representa a categoria e se propõe a pesquisar e estudar as atividades desempenhadas por tutores presenciais e a distância, incentivando e apoiando a elaboração de políticas públicas e diretrizes que tornem o trabalho do tutor mais valorizado e qualificado 4 .

Neste sentido, o movimento pela institucionalização da profissão do tutor ganha força e relevância no âmbito nacional, pois a problemática é reconhecida em diferentes espaços educativos realizados na modalidade a distância e não somente no sistema UAB. Segundo Mattar (2012), existe nas redes sociais um movimento denominado "Tutor é professor" que está crescendo e ganhando seguidores, com o intuito de pressionar as autoridades competentes para que regulamentem a profissão.

"[...] se tivesse alguma coisa voltada assim que fosse... que eu pudesse me dedicar mais, que eu pudesse estudar mais, dentro até mesmo da própria universidade, acho que teríamos mais qualidade ainda nas tutorias, embora o pessoal que eu trabalhei é de primeira, né, em todos os sentidos." (Flávia).

\footnotetext{
${ }^{4}$ http://www.tutor.anated.org.br - Acesso em 27 de dezembro de 2013.
} 
"[...] a gente quer ter um aprofundamento do nosso trabalho, a gente quer estudar, a gente quer fazer isso, mas tu precisa te identificar, né, assim como qualquer outra área de trabalho, né. Se tu vai ser um médico, tu vai ter que te especializar em alguma coisa, em alguma área, né, ou cardiologia ou ginecologia, enfim..." (Daiane).

As reivindicações de Flávia e Daiane exemplificam a necessidade de reestruturação da Educação a Distância no nosso país. A realização de cursos on demand sem a certeza de continuidade de ofertas de cursos de graduação e pós-graduação limitam as possibilidades de organização e constituição de políticas públicas que regulamentem a ação docente dos tutores a distância.

Desta maneira, a institucionalização de tutores se inviabiliza em função das incertezas de continuidade na realização de cursos EaD. Entretanto, não podemos simplesmente aceitar essa postura sem questionar e refletir sobre possíveis soluções. Com relação à estrutura da EaD, Daiane diz: "Olha, eu acho que impossível não é, mas eu acho que vai ter que ter uma reestrutura muito grande, né, porque como tá posto...". Reestruturar a organização e a oferta de cursos na modalidade EaD é uma demanda necessária e urgente.

Por conseguinte, os relatos de Daiane e Flávia tornam-se mais dotados de sentido na medida em que valorizam o trabalho desenvolvido por elas mesmas, pensando na qualidade que empenham na formação dos estudantes e também nas possibilidades de melhoria nas ações que realizam na tutoria.

Outro aspecto relevante relatado por Flávia relaciona-se à dedicação necessária para atuação na tutoria a distância. O trabalho exige do tutor atenção e responsabilidade para o acompanhamento das discussões nos fóruns, leitura das atividades e tarefas e ainda avaliação do processo de aprendizagem, tornando a junção desse material volumosa e bastante complexa.

A esse respeito, Daiane relata:

"Então foi bem puxado assim, foi bem puxado mesmo, porque a gente tinha muita coisa mesmo da EaD pra fazer, né; tinha muito trabalho pra corrigir, né; a gente tinha que corrigir os trabalho, tinha os retornos dos fóruns, né, lá dos fóruns de discussão; tinha as mensagens né. Muitas vezes elas acabavam até ligando pra gente pro celular, pro número particular, pra tirar dúvidas e tal, né, muitas das vezes; ou então deixavam recado na secretaria da EaD e a gente tinha que retornar".

A quantidade de atividades desenvolvida pelos tutores a distância também é uma marca da exploração imposta pelo sistema capitalista. Conforme os Referenciais de Qualidade para Educação Superior a Distância, do MEC (2007), um tutor atende em média trinta alunos, geralmente pertencentes ao mesmo polo, o que facilita o deslocamento de tutores para a participação em Encontros Presenciais, além de possibilitar que esse profissional possa atender os estudantes por meio da plataforma interagindo com um grupo que se constitui a partir das experiências coletivas que vivenciam.

Ao refletir sobre a quantidade de alunos atendidos podemos constatar que as formas de dominação capitalistas persuadem sobre a ação docente do tutor, limitando sua forma de participação no planejamento, organização de conteúdos e elaboração de materiais didáticos e 
avaliações, mas em contrapartida depositando altas cargas de responsabilidades no que se refere ao acompanhamento das atividades dos estudantes (MATTAR, 2012).

É na ação docente dos tutores que estão concentradas as formas de exploração características do Modo de Produção Capitalista, pois na medida em que há uma quantidade de trabalho que ultrapassa a quantidade de tempo disponível para executá-la existe a produção do sobretrabalho. Este conceito da teoria marxista refere-se ao quanto de trabalho é necessário para pagar a mão de obra do trabalhador e o quanto de trabalho excedente é necessário para a geração de lucro, ou mais valia. No contexto da EaD o lucro não é o aspecto visado pela UAB, mas sim a quantidade de estudantes atendidos com apenas um profissional. Evidenciamos que, neste contexto investigado, a tutoria a distância é um trabalho docente. Sendo assim, também compreendemos de que a estrutura organizacional da Educação a Distância vinculada ao Sistema Universidade Aberta do Brasil baseia-se na terceirização do trabalho docente na formação de nível superior, ratificando a desvalorização dos profissionais que atuam na modalidade e na manutenção contínua da exploração dos tutores.

"[...] então, muitas vezes assim, a gente fica sobrecarregado porque tu tem que corrigir prova, tu tem que corrigir trabalho, né; depois orientação de TCC; e aí busca teoria, porque cada uma quer fazer uma pesquisa diferente e aí a gente tem que buscar pra dar o suporte pras alunas" (Daiane).

Essa organização nos remete ao que Antunes (2009) pensa a respeito da mão de obra trabalhadora, cujas principais funções são dar conta do processo produtivo de acordo com os interesses primordiais da empresa. No caso da EaD, o trabalho desenvolvido pelos tutores carrega expressões significativas da classe trabalhadora que vive pressionada para cumprir com as obrigações que the cabem, carregando as marcas de uma instituição na responsabilidade com a formação profissional dos estudantes. Daiane corrobora com o exposto acima, dizendo:

"[...] então tu carrega uma marca; tu carrega uma responsabilidade, né; tu carrega a universidade. Então se eu tô carregando isso, tô carregando, né, essas marcas. Eu acho que eu tenho que ser o melhor que eu puder, né, porque eu não posso dar o meu nome; eu não posso dar o nome de uma universidade, né; eu não posso dar o nome de um curso, sem ter a responsabilidade daquilo. Então, claro a gente sempre fica com aquele receio: "não, eu tenho que dar o retorno, eu tenho que mostrar o meu trabalho, eu tenho que tá pontual nisso".

Para problematizar as responsabilidades assumidas pelos tutores, apresentamos contribuições de Antunes (2009) que diz que, se os trabalhadores não demonstrarem as aptidões, caracterizadas pelo autor como vontade, disposição e desejo, necessárias ao processo produtivo no sistema capitalista, são facilmente substituídos por trabalhadores que apresentem o perfil e os atributos para enfrentar os desafios da produção. Ou seja, a lógica do uso e descarte de trabalhadores presente no Modo de Produção Capitalista também rege a organização da Educação a Distância, pois se os tutores porventura em determinada situação deixarem de atender algum dos critérios para atuação na tutoria, um novo edital de seleção é aberto e os tutores são substituídos por outros que atendam os critérios. 
Desta maneira, a expressão "carrega" utilizada por Daiane para caracterizar suas responsabilidades demonstra o quão pesado se torna o trabalho na tutoria a distância. Isso porque as obrigações depositadas nos tutores fazem-se presentes, por exemplo, no momento em que assumem a responsabilidade de executar planejamentos pensados por professores. Na ânsia de quererem fazer o melhor em suas disciplinas, eles transferem para o tutor o desenvolvimento de seus desejos, de suas responsabilidades, pois sozinhos não dão conta da quantidade de alunos em cada disciplina; e ainda as expectativas dos estudantes que veem no tutor alguém que possa solucionar todas as suas dificuldades no processo de aprendizagem.

"[...] mas ao mesmo tempo tu vê assim: Qual é o direcionamento do teu trabalho? Qual é a validade do teu trabalho? Tu tá ali preparando... tu tá preparando profissionais, né, pra competir comigo... que é isso, né, pra fazer um concurso público. Mas qual é o direcionamento do teu trabalho? o que tu vais conduzir essas meninas a fazer, né?" (Daiane).

Os desabafos de Daiane também apontam outras questões que são relevantes no âmbito da atuação profissional, visto que os tutores se dispõem a formar novos profissionais nas mais diversas áreas, formando, dessa maneira, concorrentes para competir com eles próprios no mercado de trabalho, considerando que a tutoria, por ser um trabalho temporário, não garante a estabilidade e a permanência na função que ocupam, ficando à mercê de outras oportunidades de trabalho em outros espaços, conforme citado pela tutora.

Fica evidente que as oportunidades que a tutoria traz para a vida dos sujeitos da pesquisa são significativas, pois a participação na EaD é uma forma de se manter próximo à instituição de ensino superior e, também, de vivenciar experiências docentes que vão além do processo de aprendizagem.

"É, é verdade... até porque eu já tava afastada da FURG, um ano e meio, né; tinha me graduado, mas não tinha mais trabalhado nada, e num primeiro momento eu digo: "ai que bom, pelo menos eu ainda vou ter um vínculo com a universidade", que é uma coisa que a gente sempre quer, né" (Flávia).

Vivenciar a universidade significa, para elas, manterem-se em constante processo de formação, pois, na medida em que realizam a formação dos estudantes, estão tendo a oportunidade de ampliar seus próprios conhecimentos por meio da socialização de vivências e de partilhas de teorias. Alice diz: "porque eu tenho medo de me afastar dessa Universidade e me transformar em uma pessoa tarefeira; e eu não quero isso pra mim".

Ivana também carrega em sua fala os efeitos transformadores da tutoria em sua vida profissional:

"[...] muda a forma de ser na sala de aula... sei lá... pelas perguntas que haviam também, né, quando nós íamos no polo com os professores que eram das disciplinas de determinada disciplina... e o que eles traziam também pra nós dá pra ver que havia uma... eu chamaria até de transformação".

As transformações de que nos fala Ivana são o espelho das próprias reflexões sobre as autoimagens construídas pelas tutoras acerca das atividades que realizaram na tutoria. Arroyo (2010, p.19) faz diversos questionamentos sobre a evolução da docência ao longo da história e um deles diz: "Como não perceber que o que-fazer de mestre teve alterações profundas com 
as tentativas de incorporação desses processos "racionais" na gestão dos sistemas de ensino, na organização e divisão do trabalho?".

A exemplo citamos as palavras de Alice: "[...] no final do curso, quando fomos orientar, aí nós fomos pra categoria de professor". Mesmo desenvolvendo atividades completamente relacionadas com a formação profissional, as próprias participantes da pesquisa reconhecem que sua condição de professoras somente se deu quando o planejamento e as ações da orientação do trabalho de conclusão de curso foram repassadas integralmente para as mãos dos tutores, que nesse momento assumiram a condição de professores orientadores.

A EaD e a tutoria a distância são apenas outras formas de se vivenciar a docência carregadas com suas especificidades e suas problemáticas. Somos nós, docentes, tutores, equipes que atuam na EaD que precisamos aprender a manifestar e superar esses problemas, reivindicando para garantir condições dignas de trabalho e aprendendo a lidar com todas as situações presentes no cotidiano educacional que permeia a EaD.

Para finalizar, trago uma fala bastante significativa da tutora Leila:

"[...] eu aprendi a ser professora do ensino básico, da educação básica no fundamental, aprendi a ser professora no médio... aprendi...tô aprendendo a ser professora no universitário que não é muito diferente e aprendi a ser a distância que também não é muito diferente".

Essa fala aponta caminhos para o questionamento de Arroyo (2010) e, também, nos possibilita pensar que, para superar as dificuldades que a vida nos apresenta, é necessário refletir e aprender sempre com elas. Somos capazes de questionar e podemos superar as situações adversas sem deixar que nosso trabalho continue sendo desvalorizado.

\section{Considerações Finais}

As reflexões construídas a partir dos momentos vivenciados pelas tutoras a distância durante sua atuação no curso de Especialização em EJA na Diversidade possibilitam-nos compreender o trabalho na tutoria. Neste contexto, emergem como as maiores preocupações dos sujeitos dessa pesquisa a responsabilidade com a formação profissional e com a ação docente.

Ao evidenciar que as atividades que desenvolvem são sim um trabalho realizado por professoras qualificadas para tal, é reforçada a necessidade de maior valorização da ação educativa dos tutores conforme manifestado neste artig. A maneira simplista, conforme mencionado anteriormente, como são abordadas as funções dos tutores a distância nos documentos que deliberam sobre seu papel, não significa que na prática o trabalho desenvolvido por eles aconteça da mesma forma.

Ao contrário, as tutoras demonstram um envolvimento muito além do que realmente está previsto na legislação e regulamentação da EaD no país. Fruto de uma dedicação com o processo de formação dos estudantes, pois o foco das ações é sempre em benefício aos mesmos, o que corrobora com a perpetuação do sentimento de amor à profissão e também 
com a permanência da ingenuidade e alienação do desenvolvimento do trabalho como atividade profissional.

As vivenciadas pelas tutoras no que se refere ao acúmulo de trabalho, à instabilidade e à desvalorização na remuneração agravam a situação de exploração à qual estão sujeitas. Desta maneira, amplia-se a necessidade de intervenção, a priori, a partir de estudo científico, para que o futuro da Educação a Distância no país possa ser favorável tanto com relação ao oferecimento do ensino superior com qualidade e comprometimento, como em relação à igualdade de direitos e melhores condições de trabalho para tutores, professores e equipes multidisciplinares que atuam na organização para o funcionamento da EaD nas instituições públicas.

As estratégias para a institucionalização da Educação a Distância no Brasil ainda estão longe de serem firmadas e por isso este estudo demonstra que a utilização de prestação de serviços na área da educação precariza o trabalho docente e impede que a identidade profissional na tutoria possa ser construída e consolidada como forma de garantir, ao menos, a estabilidade de atuação e pagamento sem caracterizar o trabalho desenvolvido como terceirização da mão de obra trabalhadora.

Ao idealizar as possibilidades de institucionalização da Educação a Distância nas Universidades Públicas Federais, é necessário que sejam previstas outras formas de organização do trabalho do tutor, pois com o volume de cursos oferecidos nessa modalidade e a quantidade de estudantes atendidos pela $\mathrm{EaD}$, manter a terceirização para contratar tutores é inviável. Portanto, como estratégia para evitar baixas na qualidade dos cursos oferecidos a distância no país, os profissionais que desempenham a função de tutoria precisam conquistar seu espaço legítimo, considerando inclusive a realização de concurso público para essa função como uma das possibilidades de garantir a dedicação exclusiva para a realização do processo de formação dos estudantes.

Com relação à legitimação do tutor como um professor também é necessário que pensemos cuidadosamente nas reais atividades desenvolvidas pelos tutores, contribuindo nos debates para que se efetivem políticas públicas que regulamentem a profissão e que garantam o reconhecimento da função que exercem como docentes.

Por fim, consideramos que o trabalho do tutor a distância é essencial no desenvolvimento do processo de formativo realizado nessa modalidade de educação. É necessário, porém, que se estabeleça outra organização estrutural e pedagógica que supere as situações de exploração, alienação e precarização que as tutoras vivenciam atualmente na realização de suas funções. Face ao exposto neste artigo muitas são as demandas de trabalho desenvolvidas por esse profissional; desta maneira a desvalorização tanto financeira quanto pedagógica deve ceder espaço para a legitimação de uma profissão valorizada e necessária nas ações educativas realizadas a distância. 


\section{Referências}

ANTUNES, Ricardo. A Dialética do Trabalho. São Paulo : Expressão Popular, 2013.

Os sentidos do trabalho: ensaio sobre afirmação e a negação do trabalho. $2^{\circ}$ Ed. São Paulo: Boitempo, 2009.

ARROYO, Miguel G. Ofício de Mestre: Imagens e autoimagens. 12 Ed. Petrópolis, RJ Vozes, 2010.

BRASIL - Ministério da Educação - MEC, Secretaria de Educação a Distância - SEED/MEC. Referenciais de Qualidade para Educação Superior a distância. Brasília : Ministério da Educação: Brasília, 2007. Disponível em <http://portal.mec.gov.br/seed/arquivos/pdf/referenciaisead.pdf>. Acesso em 26 de dezembro de 2013.

DIAS, Rosilâna Aparecida; LEITE, Ligia S. Educação à Distância: da legislação ao pedagógico. 2 ed. Petrópolis, RJ: Vozes, 2010.

LOUREIRO, Carlos Frederico B. Trajetória e fundamentos da educação ambiental. São Paulo, SP : Cortez, 2004.

MATTAR, João. Tutoria e interação em educação a distância. São Paulo : Cengage Learning (Série Educação e Tecnologia), 2012.

MORAES, Roque; GALIAZZI, Maria do Carmo. Análise Textual Discursiva. Ijuí: UNIJUÍ, 2007.

VALENTE, José Armando; MORAN, José Manuel. Educação a distância: Pontos e Contrapontos. ARANTES, Valéria Amorin (organizadora) - São Paulo : Summus, 2011.

Submetido para avaliação em 17 de novembro de 2015

Aprovado para publicação em 08 de maio de 2016

\section{Fabio Alexandre Dziekaniak}

Mestre em Educação Ambiental pelo Programa de Pós-Graduação em Educação Ambiental da Universidade Federal do Rio Grande-FURG, professora da rede municipal da cidade do Rio Grande-RS, Brasil, fabitodz@gmail.com

\section{Vanise dos Santos Gomes}

Professora permanente no Programa de Pós-Graduação em Educação-PPGEDU, Dra. Em Educação pela Pontifícia Universidade Católica do Rio Grande do Sul-PUCRS, Professora Associada do Instituto de Educação na Universidade Federal do Rio Grande-FURG, Brasil, vanisegomes@furg.br

\section{Luciana Netto Dolci}

Dra. Em Educação Ambiental pelo Programa de Pós-Graduação em Educação Ambiental da Universidade Federal do Rio Grande-FURG, professora Adjunta do Instituto de Educação na mesma Universidade, Brasil, Indolci@hotmail.com 